\title{
Satisfaction on the Use of Mobility Aids Among Lower Limb Amputees and Impact on Activities of Daily Living in Selangor, Malaysia
}

\author{
Nurulizzatie Yunos ${ }^{1}$, Siti Aishah Hamzah ${ }^{2 *}$, Muhammad Hibatullah Romli ${ }^{3}$, Norafisyah \\ Makhdzir2, Aishairma Aris ${ }^{3}$ \\ ${ }^{1}$ Department of Nursing, Faculty of Medicine and Health Sciences, Universiti Putra Malaysia, \\ Selangor, Malaysia. \\ 2Department of Rehabilitation, Faculty of Medicine and Health Sciences, Universiti Putra Malaysia, \\ Selangor, Malaysia. \\ ${ }^{3}$ Department of Nursing, Faculty of Medicine, Universiti Kebangsaan Malaysia, Kuala Lumpur, \\ Malaysia.
}

\section{ABSTRACT}

Introduction: This study aims to determine the level of satisfaction on the mobility aids the dependence in activities of daily living among amputees in Bangi, Selangor.

Methods: The data was collected at Pusat Latihan Perindustrian dan Pemulihan (PLPP), Bangi in Selangor, Malaysia, on 55 lower-limb amputees using a cross-sectional design. An instrument used was adapted from Quebec User Evaluation of Satisfaction with assistive Technology (QUEST 2.0) and Barthel Index (BI). These two instruments were combined to evaluate the satisfaction of assistive aids used and dependence of activities daily living.

Results: Total mean score of level of satisfaction was $3.99(95 \% \mathrm{CI}=3.85-4.13)$ and level of dependence was $85.00(95 \% \mathrm{CI}=81.28-88.72)$. The Kruskal-Wallis test was conducted to evaluate the association of mobility aids used with level of satisfaction and level of dependence. The results showed there was no significant association between mobility aids used and level of satisfaction. Meanwhile there was a significant association between mobility aids used and dependence $(p=0.001)$. Multiple linear regression test showed the combination of mobility aids used and level of satisfaction was found significantly associated with the level of dependency $(\mathrm{p}=0.024)$. The final analysis, when only mobility aids used was included as a single variable (without the combination with the level of satisfaction), it was found statistically associated with the level of independence while the level of satisfaction score is excluded.

Conclusion: Mobility aids used was found no significant association with the level of satisfaction however, user who used cast prosthesis as mobility aids found prothesis provided them more dependency in performing activities daily living. Despite prothesis was found as the most convenience mobility aid, users did not see it as something that can give them satisfaction. This could be because of the mobility aids that provide dependency are not cost-effective. It is recommended that users can get more options to use mobility aids that can provide them dependency, nevertheless the mobility aids must be affordable for them.

Keywords: Lower-limb amputation, mobility aids, activity of daily living (ADL), satisfaction.

\section{*Corresponding author}

Siti Aishah Hamzah

Department of Nursing,

Faculty of Medicine and Health Sciences,

Universiti Putra Malaysia,

43400 Serdang, Selangor, Malaysia.

E-mail: aishahs.hamzah@upm.edu.my

\section{Article History:}

Submitted: 21 October 2021

Accepted: 04 January 2022

Published: 31 January 2022

ISSN: 2600-898X 


\section{INTRODUCTION}

Lower limb amputation accounts for approximately 65 percent of amputees [1]. In Malaysia, a recent study by Esquenia \& Yoo [2] indicates that the highest number of patients that have the amputation was because of diabetes mellitus $(53.2 \%)$ due to dysvascular, followed by traumatic wounds, which usually caused by trauma due to accidents $(24.9 \%)$. With diabetes being one of Malaysia's top five chronic diseases and motor vehicle accidents becoming one of the highest rates here compared to other countries in Southeast Asia $[3,4]$, the number of people living with lower limb amputation is expected to be significant.

Amputating a limb affects many facets of a person's life. The functional performance in daily tasks is one of the characteristics that has been considerably damaged [5, 6]. Mobility aids such as crutches, wheelchairs, scooters, walking aids and a prosthesis are recommended to compensate for the disability. The usage of prostheses among amputees was associated with individuals' physical quality of life [7]. However, multiple studies have reported users abandon mobility aids and prostheses, experience discomfort, are not suitable and give negative stigmatism [8,9]. Satisfaction is an important aspect to support the continued use of mobility aids. Studies showed the satisfaction level of mobility aids use is high among high-income countries compared to low-income countries [6, 10]. Factors such as ease of use, sophisticated and cosmetic presentation of the device and safety and comfort contribute to satisfaction [11-14]. Therefore, it is crucial to determine if the level of satisfaction on mobility aids use impacts activity of daily living function.

\section{METHODS}

Respondents with lower limb amputations registered with the Pusat Latihan Pemulihan dan Perindustrian (PLPP), Jabatan Kebajikan Masyarakat (JKM) in Bangi, Selangor, were surveyed in a cross-sectional study. This study only recruited those with a minimum age of 18 years old. They must have a unilateral or bilateral amputation and must use mobility aids for at least one month. According to the standard criteria of mobility aid, one month is sufficient for an individual to adapt and rectify any discomfort in design [9]. The respondents were registered with JKM. The total sample size for this study was 55 using universal sampling. The researcher approached the respondents, handed them an information sheet and explained the study in detail. Those who agreed to participate were asked to sign a written informed consent form and then provided with a link for an online questionnaire in a Google Form. The questionnaire took approximately 10-15 minutes to complete. The researcher shared the questionnaire link to respondents via the PLPP trainees' WhatsApp group. The PLPP's manager assists in gathering possible replies and setting up an appointment to participate in this study.

This study used a survey questionnaire to collect data. The questionnaire has two parts: part A examined demographic variables, including the respondents' age, gender, ethnicity, marital status, level of education, occupation, household income. The amputation history was also assessed in part A, including the degree of amputation, type, duration and mobility aids used. Meanwhile, Part B used the Quebec User Evaluation of Satisfaction with Assistive Technology (QUEST 2.0) [16]. It was to assess how satisfied people were with the mobility aids. There were 12 items and two dimensions. First section measured the satisfaction with assistive equipment (Items one - eight) and second section measured dependency in activity daily living (Items nine-twelve). The response format was a 5-point Likert scale, with one equaling "not at all satisfied" and five equaling "very satisfied." The mean score was used to determine respondents' level of satisfaction with assistive equipment and related services. For the scoring of device subscale score, items 1 to 8 need to add the ratings of the valid responses and divide this sum by the number of valid items in this scale and same goes to services subscale score, for items 9 to 12 need to add the ratings of the valid responses and divide this sum by the number of valid items in this scale. A higher mean score indicated a better level of satisfaction.

As reported from the previous study, the internal consistency on the instrument as overall was 0.80 . Whereby, the internal consistency score for the of satisfaction towards the mobility aids used was 0.76 [16]. 
Nevertheless, the researcher decided to re-test the instrument's reliability and the result was acceptable $(\alpha=0.73)$. In addition, there were ten items to measure respondents' independence in activities of daily living [17]. The instrument to measure the level of independent was reported in a previous study to be reliable with good internal consistency ( $\alpha=0.87-0.92)$ and having high concurrent validity $(\mathrm{r}=0.73-0.77)$ [17]. The pre-test don for the items measured the level of independent and yielded the value of 0.8 from the Cronbach alpha test. This study obtained ethical approval from the JKM (Ref No: JKMM100/12/5/2:2018/486).

\section{Statistics}

All categorical data were described using descriptive statistics of frequency and percentage, whilst continuous data were described using mean and standard deviation. Normality tests conducted on the dependence score from the sample did not normally distribute. Therefore, non-parametric analyses were chosen. Data were presented descriptively using frequency and percentage for categorical data and mean with $95 \%$ Confidence Interval $(95 \% \mathrm{CI})$ for continuous data. Kruskal-Wallis was used to examine the association between two variables, whilst multiple linear regression was used to moderate confounding by including various variables.

\section{RESULTS}

A total of 55 respondents were approached and participated in the study yielded a 100\% total rate. Among the 55 respondents, the age ranged from 18 to 60 (mean=31.62, SD =11.068). For gender, majority of the respondents were male, $75 \%(n=41)$ compared to female $25 \%(n=14)$. The result also showed a high number of Malay respondents, $80 \%(\mathrm{n}=44)$, followed by Indian $20 \%(n=11)$ and no Chinese or other ethnic groups participated. The majority of the respondents were not married, giving $64 \%$ $(n=35)$ compared to $36 \%$ of respondents who were married $(n=20)$. Slightly over half of the respondents had standard educational levels giving the percentage of $64 \%(n=35)$ compared to $36 \%(n=20)$ who had obtained a higher level of education.

From the occupational status, slightly more than half of the respondents were unemployed
(64\%; $n=35)$, followed by self-employed ( $24 \%$; $\mathrm{n}=13)$. Meanwhile, $7 \%$ worked in private

Table I. Socio-demographic characteristic among respondents

\begin{tabular}{|c|c|c|c|}
\hline Variables & $\mathbf{N}$ & $\%$ & $\begin{array}{l}\text { Mean } \\
\text { (SD) }\end{array}$ \\
\hline Age & & & $\begin{array}{l}31.62 \\
(11.07)\end{array}$ \\
\hline \multicolumn{4}{|l|}{ Gender } \\
\hline Male & 41 & 75 & \\
\hline Female & 14 & 25 & \\
\hline \multicolumn{4}{|l|}{ Ethnicity } \\
\hline Malay & 44 & 80 & \\
\hline Indian & 11 & 20 & \\
\hline \multicolumn{4}{|l|}{ Marital Status } \\
\hline Single & 35 & 64 & \\
\hline Married & 20 & 36 & \\
\hline \multicolumn{4}{|l|}{ Level of Education } \\
\hline Low education & 35 & 64 & \\
\hline level & 20 & 36 & \\
\hline \multicolumn{4}{|l|}{ High education } \\
\hline \multicolumn{4}{|l|}{ level } \\
\hline \multicolumn{4}{|l|}{ Occupation } \\
\hline Unemployed & 35 & 64 & \\
\hline Civil Service & 3 & 5 & \\
\hline Private Sector & 4 & 7 & \\
\hline Self- employed & 13 & 24 & \\
\hline \multicolumn{4}{|l|}{ Household Income } \\
\hline RM 500- RM 999 & 7 & 13 & \\
\hline RM 1000- RM 1499 & 14 & 25 & \\
\hline RM 1500- RM 1999 & 7 & 13 & \\
\hline RM 2000- RM 2499 & 14 & 25 & \\
\hline RM 2500- RM 3000 & 7 & 13 & \\
\hline RM 3000 and above & 6 & 11 & \\
\hline \multicolumn{4}{|l|}{ Level of Amputation } \\
\hline Unilateral & 51 & 93 & \\
\hline Bilateral & 4 & 7 & \\
\hline \multicolumn{4}{|l|}{ Type of Amputation } \\
\hline Transfemoral & 12 & 22 & \\
\hline (above-knee & 4 & 7 & \\
\hline amputation) & 37 & 67 & \\
\hline Knee & 2 & 4 & \\
\hline \multicolumn{4}{|l|}{ Disarticulation } \\
\hline \multirow{2}{*}{\multicolumn{4}{|c|}{$\begin{array}{l}\text { Transtibial (below- } \\
\text { knee amputation) }\end{array}$}} \\
\hline \multirow{2}{*}{\multicolumn{4}{|c|}{$\begin{array}{l}\text { knee amputation) } \\
\text { Syme's amputation }\end{array}$}} \\
\hline & & & \\
\hline $\begin{array}{l}\text { Duration of mobility } \\
\text { aid used }\end{array}$ & & & $\begin{array}{l}4.22 \\
(3.61)\end{array}$ \\
\hline
\end{tabular}

sectors $(n=4)$ and $5 \%$ worked in civil services $(n=3)$. From the context of the household income distributions, $51 \%$ of respondents had 
less than RM2000and $49 \%$ of the respondents had more than RM2000.

Regarding the respondents' amputation information, $93 \%$ of the respondents were unilateral amputees $(n=51)$ and only $7 \%(n=4)$ respondents were bilateral amputees. Regarding the type of amputations, $67 \%(n=37)$ respondents' amputation was transtibial (below knee amputation), followed by $22 \%$ $(n=12) \quad$ were transfemoral (above-knee amputation), $7 \%$ were knee disarticulation $(n=4)$ and $4 \%(n=2)$ were Syme's amputation. Detail information on the demographic characteristics of the respondents is presented in Table I.

In the context of mobility aids, the respondents used mobility aids such as manual wheelchairs, motorized wheelchairs, crutches, walkers, cane and prosthetic limbs (Refer to Figure I). They used mobility aids ranging from one year to 13 years, with a mean duration of 4.22 years $(\mathrm{SD}=3.614)$. The majority of the respondents used mobility aids less than five years $(78 \%$, $\mathrm{n}=43$ ), only $9 \%$ used it for more than ten years $(\mathrm{n}=5)$.

Mean score was used to assess the respondents' satisfaction towards the mobility aids (refer to Table II). The respondents reported the highest satisfaction in using axilla crutches (4.17), followed by standard walker (4.17), standard wheelchair (4.01), prosthesis (3.99), powered wheelchair (3.95) and off-set cane (3.25). Figure I: Numbers of mobility aids use by the
participants $(\mathrm{N}=55)$

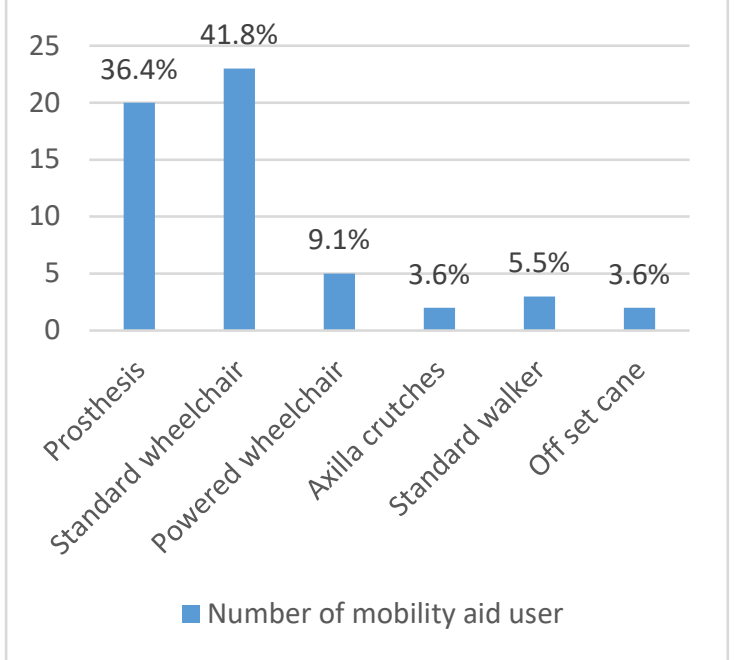

On the other hand, the mean score assessed the level of dependencies in using mobility aids (refer to Table II). Respondents reported using a prosthesis gave them the highest level of dependencies (94.5), followed by axilla crutches (92.5), off-set cane (85.00), powered wheelchair (82.00), standard walker (79.13) and standard wheelchair (65.00).

Kruskal-Wallis test analyses were conducted to evaluate the association between user satisfaction and independence with the mobility aids used. This study found no significant association between mobility aids used and level of satisfaction $(p=0.359)$. Nevertheless, the association between the mobility aids used and level of independence was significant $(p<0.001) \quad($ refer Table II). Further analysis was conducted on the association between mobility aids used and level of independence using Dunnet T3 posthoc test and found that prosthesis $(p<0.001)$ users had more independence in activity daily living compared to using a standard wheelchair $(p=0.001)$ and standard walker $(\mathrm{p}<0.001)$.

Because mobility aids were found significantly associated with the level of dependency, advanced analysis was conducted using Multiple Linear Regression by including the level of satisfaction score as the primary independent factor and mobility aids used as a confounding factor. In contrast, the level of dependency score was the dependent variable. Enter option was used to force both variables in the analysis as the level of satisfaction was considered the primary observation. Hence, a limited number of variables could be allowed for selective finding [18]. The result showed the combination of mobility aids used and level of satisfaction was found significantly associated with the level of dependency $(p=0.024)$. Meanwhile, in the final analysis, when only mobility aids used was included as a single variable (without the combination with the level of satisfaction), it was found statistically associated with the level of independence $(\beta=-$ 0.335 , SE $\beta=1.370, p=0.013$ ) whilst the level of satisfaction score is excluded $(\beta=0.118$, SE $\beta$ $=3.515, \mathrm{p}=0.367$ ) 
Table II: Association between mobility aids use with level of satisfaction and level of independence in activities of daily living.

\begin{tabular}{lclllll}
\hline Variables & N (\%) & Score mean 95\% CI & $\begin{array}{l}\text { Mean } \\
\text { Rank }\end{array}$ & df & F & $p$-value \\
\hline \multicolumn{2}{l}{ level of satisfaction (QUEST 2.0) } & & & & & \\
\hline Mobility aids & $20(36)$ & $3.99(3.67-4.31)$ & 29.35 & 5 & 1.017 & 0.359 \\
Prosthesis & $23(42)$ & $4.01(3.85-4.18)$ & 27.78 & & & \\
Standard wheelchair & $5(9)$ & $3.95(3.59-4.31)$ & 24.90 & & & \\
Powered wheelchair & $2(4)$ & $4.21(3.68-4.74)$ & 35.00 & & & \\
Axilla crutches & $3(5)$ & $4.17(3.45-4.88)$ & 36.17 & & \\
Standard walker & $2(4)$ & $3.25(0)$ & 5.50 & & \\
Off set cane & & & & & & \\
\hline level of independence in activities of daily living (BI) & & & & \\
\hline Mobility aids & $20(36)$ & $94.50(89.30-99.70)$ & 41.04 & 5 & & \\
Prosthesis & $23(42)$ & $79.13(73.97-84.29)$ & 20.04 & & \\
Standard wheelchair & $5(9)$ & $82.00(66.42-97.58)$ & 21.80 & & \\
Powered wheelchair & $2(4)$ & $92.50(0)$ & 35.50 & & \\
Axilla crutches & $3(5)$ & $65.00(0)$ & 8.00 & & \\
Standard walker & $2(4)$ & $85.00(0)$ & 26.50 & & \\
Off set cane & & &
\end{tabular}

\section{DISCUSSION}

Mobility aids play a vital role in ADL and show that prosthesis has better daily functions than other mobility aids. Herrera-Saray and colleagues [9] indicate that prostheses play the parts to help to maintain body image and selfesteem and this may influence the satisfaction level. However, satisfaction only is not the main factor influencing independence as functional performance is a must-do activity in daily human life.

Financial constraints could be one factor that influences an individual to choose which type of mobility device to use. The respondent satisfied with the mobility aid that was more cost-effective to them. In addition, majority of the respondent used mobility aids for less than five years. Cost factor's consideration could become a factor that led them to reported satisfaction. Moreover, mobility aids, including prostheses and wheelchairs, are classified as assistive technology. These mobility aids are more expensive than non-technology assistive devices such as axillary crutches and cane. Hence, this could be why the respondent reported the highest level of satisfaction in using axillary crutches whilst they claim prosthesis could provide more dependency. Issues such as service maintenance and repair would be a significant source of dissatisfaction $[19,20]$. The organization that supplies mobility aids for disabled individuals has a limited budget to ensure the availability of technology assistive aids. To get the aids that could provide more dependency, they have to wait for a considerable period [21]. This situation may result in the individuals functioning in an optimal condition even though having low satisfaction with the prosthesis and may explain the findings. Therefore, one-off support for prosthetics is prioritized to the low income whilst others in-waiting need to use the most affordable mobility aids available. The high number of prosthesis users in this study is concordance on PLPP focus on vocational training; therefore, prosthesis use is the best option as prosthesis supports optimal functional performance [7, 22-24].

Some studies found mobility aids (i.e., prosthesis, motorized wheelchair) with the farthest range of mobility given the lowest satisfaction. These studies justified that there may be due to when more functional 
performance can be done more challenges are anticipated [20,21]. The authors also assumed that the person might become uncomfortable due to a more extended period of mobility aids. More technology is used in mobility aids. The more people can observe one's disability and give hostile receptions to the person with disabilities [20,21]. On the other hand, another type of mobility aids which are cheaper but provide the limited ability for the person to move farther due to the need to use their effort and energy to use it and they found it uneasy about maneuvering the device.

Moreover, the mobility aids such as wheelchairs and crutches become an extra part of the body, contributing to hassle when individuals do outdoor activities. Hence, they prefer not to use it more often to avoid showing their vulnerability, influencing other people's perceptions of them. Still, instead, their perception of themselves influenced how they anticipated other people's views of them. However, this assumption is still implicit and needs to be explored in further study.

This study's satisfaction level was slightly lower than a previous study done in Malawi [6] but marginally better than that conducted in Laos [25]. Satisfaction level might be influenced by various factors such as cultural experience, socio-economic perspective, knowledge, exposure and user perspective [26]. Therefore, the determinant of satisfaction must need to be explored from various socio-economic contexts.

In this present study, even though respondents reported dependency on performing ADL by using a specific type of mobility device, their dependency did not influence their satisfaction. A study in Australia supports this finding found no association between satisfaction and functional ability [26]. The current research contradicts a local study that found mobility aids are associated with operational performance and, in turn, satisfied the people who are using them [24]. However, that study did not control the confounding factors that might contribute to the satisfaction. Hence, the comparison cannot give any significant value for this present study.

In conducting the study, time constrain became a significant limitation. The time constrain explained why there was a small sample size. Nevertheless, the limited number of people who use mobility aids under certain circumstances limits their mobility. Hence the small sample size was justifiable to contribute significant knowledge on the topic. Although a finding shows that people with disabilities can perform their functional activities independently even with equipment constraints, their satisfaction does not interfere with their daily performance [27]. The researcher's access to enter the study setting and getting the first-hand data from the disabled people was seen as an impactful opportunity to understand their experiences. However, future studies may be helpful if the researcher can collect the data from a broader population, be it from the people registered with JKM, the patients at the hospital, or people who sustained an acute traumatic injury needing medical use aids temporarily. Hence, the finding of this study could provide a piece of helpful information for future research.

\section{CONCLUSION}

This study is one of the foundations on the importance of performing basic ADL and mobility aids options and the satisfaction among amputees. It shows that prosthesis is one of the essential aids to amputees in choosing mobility aids. It is vital to cast the prosthesis's preparation in increasing the satisfaction and activity of daily living can be performed as soon as possible after a disability occurs. Healthcare practitioners should emphasize proper stump surgery, care and management to ensure the stump has good shape, soft and flexible condition [29]. This emphasis will allow the prosthesis cast to be made more comfortable, smooth and easy fit. However, policymakers and developers should consider the cosmetic and aesthetic value of mobility aids should be made not too revealed; the same with the mechanical view to make it as 'normal' as possible to ensure the dignity of the users. Making the aids look sophisticated may benefit from elevating the social perception from the public on the person with disabilities [6, 8-10]. Comfortability is another aspect that the developers and researchers should emphasize. The person with disabilities spends more time with the aids. Therefore, they need to be comfortable using the aids. These 
will indirectly improve the satisfaction level of the persons.

\section{CONFLICT OF INTEREST}

There was no significant conflict of interest expected for this study.

\section{ACKNOWLEDGEMENT}

Staff in PLPP Bangi for cooperation and all respondents who were participating in this study.

\section{REFERENCES}

1. Esquenia A, Yoo SK. Lower limb amputations epidemiology and assessment. PMER Knowledge Now. 2012.

https://now.aapmr.org/lower-limbamputations-epidemiology-andassessment/

2. Ab Rahman NLA, Arifin N, Hasbollah HR, Noor Azman NN , Hanafi MH, Ibrahim A, et al. Trends in incidence of lower extremity amputations in Malaysia: a populationbased study. Int J Recent Res Soc Sci Humanit. 2017; 4(4): 57-61.

3. Institute for Public Health. National Health and Morbidity Survey - Vol. II: NonCommunicable Diseases, Risk Factors $\mathcal{E}$ Other Health Problems. Malaysia: Ministry of Health. 2015

4. Darma Y, Karim MR, Abdullah S. An analysis of Malaysia road traffic death distribution by road environment. Sādhanā. 2017; 42(9): 1605-15

5. Ebrahimzadeh MH, Moradi A, Bozorgnia S, Hallaj-Moghaddam M. Evaluation of disabilities and activities of daily living of war-related bilateral lower extremity amputees. Prosthet Orthot Int. 2016; 40(1): 5167

6. Magnusson L, Ahlström G, Ramstrand N, Fransson EI. Malawian prosthetic and orthotic users' mobility and satisfaction with their lower limb assistive device. J Rehabil Med. 2013; 45(4): 385-91

7. Abdul Razak MM, Tauhid MZ, Yasin NF, Hanafiah FA. Quality of Life among Lower Limb Amputees in Malaysia. Procedia - Soc Behav Sci. 2016; 222: 450-7

8. Sinha R, Van Den Heuvel WJ. A systematic literature review of quality of life in lower limb amputees. Disabil Rehabil. 2011; 33(11):
883-99

9. Herrera-saray P, Peláez-ballestas I, Ramoslira L, Sánchez-monroy D. Usage problems and social barriers faced by persons with a wheelchair and other aids qualitative study from the ergonomics perspective in persons disabled by Rheumatoid Arthritis and other conditions. Reumatología Clínica. 2013; 9(1): 24-30.

10. Pezzin LE, Dillingham TR, Mackenzie EJ, Ephraim PL, Rossbach P. Use and satisfaction with prosthetic limb devices and related services. Related Services. 2004; 85(5): 723-9

11. Evans S. Older adults' use of, and satisfaction with, electric powered indoor/outdoor wheelchairs. Age Ageing, 2007; 36(4): 431-5.

12. Jedeloo S, Witte LD, Linssen B, Schrijvers G. Satisfaction with and use of assistive devices and services for outdoor mobility. Technol Disabil. 2000; 13(3): 173-81.

13. Mohanty RK, Lenka P, Equebal A, Kumar R. Comparison of energy cost in transtibial amputees using 'prosthesis' and 'crutches without prosthesis' for walking activities. Ann Phys Rehabil Med. 2012; 55(4): 252-62.

14. Bateni H, Maki BE. Assistive devices for balance and mobility: benefits, demands, and adverse consequences. Arch of Phy Med and Rehabil. 2005; 86: 134-45

15. In a conversation with the Director of the PLPP (January 2019)

16. Demers L, Weiss-lambrou R, Ska B. The Quebec User Evaluation of Satisfaction with Assistive Technology (QUEST 2.0): an overview and recent progress. Technol Disabil. 2002; 14(1): 101-5

17. Wade DT, Collin C. The Barthel ADL Index: a standard measure of physical disability? Int Disabil Stud. 1988; 10(2): 64-7

18. Barton B, Peat J. Medical Statistics: A Guide to SPSS, Data Analysis and Critical Appraisal (2 ${ }^{\text {nd }}$ ed). Sydney: Wiley-Blackwell \& BMJ Books

19. Fomiatti R, Richmond J, Moir L, Millsteed J. A systematic review of the impact of powered mobility devices on older adults' activity engagement. Phys Occup Ther Geriatr. 2013; 31 (4): 297-309.

20. Borg J, Lindström A, Larsson S. Assistive technology in developing countries: a review from the perspective of the Convention on the Rights of Person with Disabilities. Prosthet Orthot Int. 2011; 33(1): 20-9 
21. Islam MR. Rights of the people with disabilities and social exclusion in Malaysia. Int J Soc Sci Humanit. 2015; 5(2): 171-7

22. Ghani MZ, Che Ahmad A, Sulaiman NA, Kajian keberkesanan program latihan orang kurang upaya (OKU) di Pusat Latihan Perindustrian dan Pemulihan (PLPP) di Bangi, Malaysia: Monograph Series. 2015. Penang: Universiti Sains Malaysia.

23. Kahle JT, Highsmith MJ, Hubbard SL. Comparison of nonmicroprocessor knee mechanism versus C-Leg on prosthesis evaluation questionnaire, stumbles, fall, walking tests, stair descent and knee preference. J Rehabil Res Dev. 2008; 45(1): 114

24. Vetrayan J, Abd Ghafar N, Paulraj SJPV, Murad MS. Occupational performance role and satisfaction among lower limb amputees with different adaptive devices usage. Procedia- Soc Beh Sci. 2016; 222: 43241.

25. Durham J, Sychareun V, Santisouk P, Chaleunvong K. User' satisfaction with prothesic and orthotic assistive devices in the Lao people's democratic republic: A Cross-sectional study. Disabil CBR Incl Dev. 2016; 27(3): 24-44.

26. Kark L, Simmons A. Patient satisfaction following lower-limb amputation: The role of gait deviation. Prosthet Orthot In. 2011; 35(2): 225-33.

27. Murad MS, Idris SNH, Kannan C, Danis A. Impact of occupationally based intervention program in relation to quality of life of spinal injury people. Procedia-Soc Beh Sci. 2016; 222: 442- 449.

28. Romli MH, Wan Yunus F, Mackenzie L. Overview of reviews of standardized occupation-based instruments for use in occupational therapy practice. Aust Occup Ther J. 2019; 66(4): 428-45

29. Bryant G. Stump care. Am J Nurs. 2001; 101(2): 69-71 